\title{
Perceptions and Nursing Demands and Experiences in the Midst of an International Crisis (PANDEMIC): A Qualitative Study of Nurse Educators' Experiences
}

\author{
Lorelli Nowell \\ University of Calgary, Inowell@ucalgary.ca \\ Swati Dhingra \\ University of Calgary, swati.dhingra@ucalgary.ca \\ Kimberley Andrews \\ University of Calgary, kimberley.andrews@ucalgary.ca \\ Jennifer Jackson \\ University of Calgary, jennifer.jackson1@ucalgary.ca
}

Follow this and additional works at: https://qane-afi.casn.ca/journal

Part of the Higher Education and Teaching Commons, and the Nursing Commons

\section{Recommended Citation}

Nowell, Lorelli; Dhingra, Swati; Andrews, Kimberley; and Jackson, Jennifer (2021) "Perceptions and Nursing Demands and Experiences in the Midst of an International Crisis (PANDEMIC): A Qualitative Study of Nurse Educators' Experiences," Quality Advancement in Nursing Education - Avancées en formation infirmière: Vol. 7: Iss. 2, Article 8. DOI: https://doi.org/10.17483/2368-6669.1291

This Article is brought to you for free and open access by Quality Advancement in Nursing Education - Avancées en formation infirmière. It has been accepted for inclusion in Quality Advancement in Nursing Education - Avancées en formation infirmière by an authorized editor of Quality Advancement in Nursing Education - Avancées en formation infirmière. 


\section{Introduction}

Nurse educators, of whom $93.2 \%$ are women, are crucial to educating and supporting the nursing workforce (National League for Nursing, 2017). The COVID-19 pandemic provoked widespread disruption to nurse educators' work, both within higher educational institutions and practice learning environments. At the beginning of the COVID-19 pandemic, nurse educators took unprecedented steps to continue their work while creating alternative forms of education, including simulation, distance learning, and telehealth (Hassmiller et al., 2020; Langlois et al., 2020).

The pandemic forced nurse educators to be innovative and nimble as they faced difficult decisions on how best to support their clinical colleagues and nursing students (Dewart et al., 2020). The rapid shift to online and remote learning had a significant impact on the role of nurse educators. Many nurse educators have no or limited experience in developing and delivering education online (Sword, 2012). Additionally, nurse educators experienced an urgent need to support nurses and other health care providers with up-to-date COVID-19 evidence and changing precautions and policies (Nashwan et al., 2020). It is important to consider the implications of nurse educators' shift in focus.

\section{Literature Review}

The onset of COVID-19 resulted in a sudden move to "emergency remote teaching" in both higher education and clinical nursing contexts (Costa et al., 2020). Nurse educators were pressed to make sweeping changes to widely adopt simulation, distance learning, and telehealth (Hassmiller et al., 2020). While online learning has increased over the past decade (Hachey et al., 2012), it is usually carefully and purposefully designed. The rapid response to COVID-19 meant nurse educators did not have the luxury of time. Furthermore, educators often have limited awareness of and proficiency with online teaching technology (Oblinger \& Hawkins, 2006), and few educators have developed shared epistemic agency for leading these innovations (Jacobsen et al., 2013). Nurse educators have faced significant challenges with remote teaching, including availability of resources, tools, and cognitive bandwidth (Klar, 2020). Through this research, we aimed to gain a more comprehensive understanding of nurse educators' experiences during the pandemic.

\section{Methods}

\section{Context}

We employed a sequential-explanatory mixed methods design (Creswell, 2014) including a cross-sectional survey and qualitative interviews. In the first phase of our Perceptions And Nursing Demands and Experiences in the Middle of an International Crisis (PANDEMIC) study, we used a cross-sectional survey to explore nurses' experiences of COVID19, the impact the pandemic has had on nursing work, and identify potential opportunities and strategies to support the nursing workforce. Registered nursing professionals in any role, anywhere around the world, were eligible to participate and recruited via social media platforms that included a link to an online survey (Topolovec-Vranic \& Natarajan, 2016). During analysis we found the experiences of nurse educators were sufficiently unique to warrant further investigation, leading to this second qualitative phase of our PANDEMIC study. Integration between the two phases occurred when selecting interview participants for phase two based on phase one survey results. 
The interview protocol was developed based on the survey results to investigate the survey results in more depth.

\section{Design}

A pragmatic worldview was used to underpin the larger mixed methods research study. A pragmatic viewpoint offers epistemological justification for bringing together multiple sources of knowledge to gain a greater understanding of social problems (Johnson \& Onwuegbuzie, 2004). Pragmatism is not committed to one system of philosophy, and drawing on this worldview, allowed us to draw from quantitative and qualitative methods, techniques, and procedures to best meet our research needs and purposes (Creswell, 2014). For this second qualitative phase of the mixed methods study, we used a qualitative thematic analysis design (Braun \& Clarke, 2006) underpinned by pragmatic philosophy (Nowell, 2015) to gain a comprehensive understanding of nurse educators' experiences during the pandemic. Thematic analysis is a highly flexible methodology that can result in rich, multifaceted accounts from a variety of research participants, underlining similarities and differences, as well as unanticipated insights (Braun \& Clarke, 2006).

\section{Sampling Strategy}

All PANDEMIC survey participants were asked if they would like to be contacted for a follow up interview. A total of 45 nurse educators completed our survey and 35 indicated their willingness to be contacted for a follow up interview. All nurse educators who indicated their willingness to be contacted for an interview $(N=35)$, regardless of location, were emailed and invited to participate in this qualitative study.

\section{Ethics}

We obtained institutional ethics approval for this study (REB20-0633), and nurse educators provided written and verbal consent before the interviews.

\section{Data Collection}

Semi-structured interviews were conducted via telephone and zoom and lasted between 30 and 45 minutes. Data collection occurred between June and July 2020 and continued until data saturation was achieved (Miles et al., 2014). All interviews were allocated a unique identifier, digitally recorded, transcribed verbatim, and anonymized. Transcripts were then imported into NVivo (version 12) to organize and support data analysis. The following questions were included in our semi-structured interview guide:

1. Can you tell me about your current role?

2. How many years have you been in this role?

3. What are your main responsibilities in your current role?

4. Has your work changed since COVID-19?

5. How do you feel about these changes?

6. Were you surprised by anything that has happened with COVID?

7. Which aspect of your work is the most difficult and why?

8. How are you managing these changes?

9. What is working well? What has not worked?

10. What would you want leaders to know about how these changes have impacted your work?

11. Do you have any recommendations about how to best move forward?

12. Is there anything else you'd like to tell me that we have not already talked about? 


\section{Data Analysis}

We used thematic analysis methods and processes to guide the phases of data analysis (Braun \& Clarke, 2006). Researchers first independently reviewed the transcripts and began to formulate provisional codes and themes. Weekly coding meetings with the research team created mutual understanding of codes and helped refine the coding framework. Teams of two coders examined and assigned sections of text to codes, representing themes or subthemes. Data were coded to as many themes/subthemes as relevant and memos were used to record emerging impressions or interesting aspects of the data. Themes were further refined and reduced by examining coherent patterns in the coded data extracts.

\section{Trustworthiness}

We used several techniques to maximize the trustworthiness of study findings. Team meetings provided a venue for reflexivity, debriefing, and questioning of our interpretations and stance (Morse, 2015). We maintained a detailed audit trail of all decisions (Carnevale, 2016), including a codebook, meeting minutes, and file-naming conventions. Teams of two researchers coded all transcripts, and decisions about themes and subthemes were vetted within the team (Morse, 2015). We returned to the raw data to further verify our results and ensure that all themes and subthemes adequately reflected the participant voices (Morse, 2015).

\section{Findings}

\section{Participant Demographics}

Fifteen nurse educators from the 35 invited, participated in interviews and the majority were from Canada (67\%), female (80\%), and White (87\%) (Table 1). All of the participants had a bachelor's degree as the minimum level of education, and $33 \%$ had a $\mathrm{PhD}$.

\section{Table 1}

Participant Demographics

\begin{tabular}{llcc}
\hline Characteristics & $\boldsymbol{n}$ & $\boldsymbol{\%}$ \\
\hline Country & Australia & 1 & 6.7 \\
& Canada & 10 & 66.7 \\
& Ireland & 1 & 6.7 \\
& Kenya & 1 & 6.7 \\
& United Kingdom & 1 & 6.7 \\
& United States & 1 & 6.7 \\
Gender & Female & 12 & 80.0 \\
& Male & 3 & 20.0 \\
Age & 25-34 years & & \\
& 35-44 years & 3 & 20.0 \\
& 45-54 years & 4 & 26.7 \\
& 55+ years & 4 & 26.7 \\
& & 4 & 26.7 \\
Ethnicity & Asian & & \\
& Black & 1 & 6.7 \\
& & 1 & 6.7 \\
\hline
\end{tabular}




\begin{tabular}{llcc}
\hline & White & 13 & 86.7 \\
Education & Bachelor's degree & 4 & 26.7 \\
& $\begin{array}{l}\text { Post-diploma certificate } \\
\text { Master's degree in }\end{array}$ & 1 & 6.7 \\
& nursing & 4 & 26.7 \\
& Master's degree other & 1 & 6.7 \\
& PhD in nursing & 5 & 33.3 \\
Years in & Less than 1 year & 4 & 26.7 \\
current & 1-4 years & 4 & 26.7 \\
position & 5-9 years & 3 & 20.0 \\
& 10-14 years & 2 & 13.3 \\
& 15-19 years & 2 & 13.3 \\
Primary & Clinical education & 7 & 46.7 \\
work setting & Academia & 8 & 53.3 \\
& & & \\
\hline
\end{tabular}

In our analysis, a sailing metaphor embodied the themes that emerged. There was an overarching sentiment that "we are all in this together" and that nurse educators around the globe were all facing similar challenges.

We do have quite a different health care system, but it's funny how it's just the same things... no matter where you are, we all face the same problems. And it's remarkable how you get that camaraderie, I suppose, with nurses even no matter where they are and no matter what system they're working in, at the end of the day, we were all trying to do the same thing. And I just think that's nice to know; actually, it's kind of reassuring. (P3, clinical educator)

In the subsequent sections, we provide a detailed analysis of the themes and subthemes that emerged and provide a high-level overview in Table 2.

\section{Table 2}

Themes and Subthemes

\begin{tabular}{ll}
\hline Themes & Subthemes \\
\hline The calm before the storm & \\
Battening down the hatches & $\begin{array}{l}\text { Changing work focus } \\
\text { Changing work delivery } \\
\text { Changing education content }\end{array}$ \\
Weathering the storm & $\begin{array}{l}\text { Coping with rapid changes } \\
\text { Struggling to stay afloat } \\
\text { Lacking support and resources }\end{array}$
\end{tabular}


Silver linings

Shedding light on the value of nurses

Increasing collaboration

Swimming not sinking

\section{Theme One: The Calm Before the Storm}

We asked nurse educators about their regular work duties and roles before the pandemic. Several participants reported development and delivery of face-to-face, simulation, and virtual education as part of their roles. Nurse educators spoke frequently about ongoing education including recertification, just-in-time teaching, clinical support, and mentorship as part of their nurse educator role. Those working in academia devoted a significant amount of their time to research alongside committee and community work: "My role encompasses a degree of research as well as commitment to service... on a number of external committees" (P10, academic educator). In contrast, nurse educators working in clinical settings spoke about dissemination of information to keep the staff updated and informed: "I'm responsible for ensuring nursing quality through education. So any updates that come out, any new procedures or processes" (P1, clinical educator). Nurse educators in both academic and clinical settings indicated their role comprised a variety of activities to ensure quality nursing care.

\section{Theme Two: Battening Down the Hatches}

\section{Changing Work Focus}

Participants expressed concerns regarding the changing work priorities, often resulting in a deferral of their everyday work: "COVID threw everything else out the window that we were working on" ( $\mathrm{P} 1$, clinical educator), and "within days we tabled all of that simulation and we became just COVID focused" (P4, clinical educator). For nurse educators working in academic settings, the cancellation of programs and suspension of research was concerning: "Everything research-wise closed and it included all types of research... all of those all of a sudden came to a halt" (P5). The implication was that nurse educators had to abandon other priorities in favour of pandemic-related work and adapt rapidly to a new focus in their roles.

Many nurse educators, coped by accepting and adapting to new ways of working: "The adrenaline was there and now it's... more into adapting and acceptance that this is the way things are right now. And that they're going to be like this for a while" (P12, clinical educator). There was also a sense of knowing that nurse educators had the skills and knowledge to overcome the crisis: "It's challenging, but it can be done... everything is hard, but it can be done" (P13, clinical educator). This confidence helped participants to adapt their work despite significant changes.

\section{Changing Work Delivery}

A great part of nurse educator work was spent preparing for the uncertainties of the pandemic: "Everything is going to have to go behind getting prepared now for whatever uncertainties we'll have" (P11, academic educator). Groundwork activities in clinical settings included planning for potential capacity concerns and management of patient flow. In academic settings, the focus turned to adapting to online systems and developing work-from-home strategies: "I had to organize so that everyone had what they needed to be able to access their work from home and adjust to the home environment for our team" (P14, academic educator). Participants also indicated they had to redesign course and preparatory materials to facilitate online education: 
I thought we might need to prepare to go online... I could see that there might be challenges with clinical practice... I told staff to prepare to go online... that they were starting to think about how they might transition their content to an online delivery mode. (P10, academic educator)

Educational delivery was modified to minimise the risk of transmission of COVID-19. Nurse educators generally work closely with those they teach, and they were forced to change to online systems as face-to-face communication was reduced or stopped altogether. This new work environment meant nurse educators were learning new technology or platforms to perform their work amid the constant changes to information and workflow. Ongoing education of staff and students challenged participants to find new ways to teach in an online environment. These changes required increased resourcefulness and a different way of thinking. Nurse educators in academic settings identified the use of different and flexible ways of meeting student needs to optimise student learning: "Now that we have these opportunities and experiences... why not gather all of the positive things about online learning and incorporate it into our current or new curriculum" (P8, academic educator). Clinical educators working in acute care settings spoke about the excitement of new opportunities:

We need to put some energy and excitement into that to be forward thinking... in crisis there's opportunity... we can do some things differently here and it's exciting. So tapping into that excitement and keeping it energized... that's something we have to pay some attention to as well. (P11, academic educator)

These points highlight that although the changes to education delivery were rapid and unexpected, key learnings from the experience could be carried forward into future nurse educator practice.

\section{Changing Education Content}

The pandemic resulted in high volumes of information that required distillation and dissemination to be shared in targeted key messages for staff and students: "The documents were not coming out in easy-to-digest format... something comes out that we're supposed to implement and we all digest it for our unit and make some things easier to read" (P1, clinical educator). This challenge was compounded by high-level documents that were lengthy or difficult to interpret, with conflicting information from different healthcare related organizations or departments: "But with COVID, with the rapidity of change and some contradiction of different information and reference sources, that communication has been even more important" (P2, clinical educator).

Despite the rapid changes, clinical nurse educators remained focused on educating and keeping the staff up-to-date with COVID-19 guidelines. A substantial amount of time was devoted to sharing changes to policies and procedures with the staff. These communication challenges pushed nursing educators to try innovative approaches beyond conventional email or face-to-face communication, including social media and technology platforms: "We had to be creative in how we got our message out from daily huddles, from email, from checking in with staff and persons. I created an Instagram account for the emergency department staff, just as another layer of communication" (P2, clinical educator). Targeted messaging using multiple methods of communication was a new component of their COVID-19 education routine. They used innovative strategies to manage the deluge of information, including posters in high visibility areas, infographics, COVID-19 resource binders, slide shows on the break room TVs, and social media (Instagram, WhatsApp, Cielo). One participant spoke about communication solutions that were 
mindful of the need for physical distancing: "So, figuring out how we're going to communicate inside and out of these rooms for all of these resuscitations... we ended up using a combination of baby monitors and walkie-talkies and then creating videos to help staff figure out how the new process would look" (P9, clinical educator).

Nurse educators who were teaching in academic settings described a disruption to normal workflow for disseminating information; normal timeframes and methods of communication were no longer sufficient:

Let's say a student would have a question, he or she will send that to me via email or post it on the discussion board. By the time I get to the question and answer the question, hours have gone by already. Versus when I have them in class, somebody would ask a question, all I would have to do is get everyone's attention, we answer that question then we move forward. (P8, academic educator)

Despite these challenges, nurse educators remained committed to staying connected to their staff and students and supporting continued education.

\section{Theme Three: Weathering the Storm}

\section{Coping With Rapid Changes}

The rapidly evolving pandemic required nurse educators to manage large volumes of consistently moving and changing information: "It's been an intense pace of changes... I do not think this has ever happened, the number of changes consistently and constantly happening. That has been a big portion of the work, a big change with COVID" (P1, clinical educator). Clinical nurse educators were concerned about the lack of time to analyse new policies and procedures and struggled to keep up with the constant changes. To manage the intense pace of change, participants spoke about the need to slow down and think through the changes and then plan accordingly: "Let's stand back. Let's pause and let's assess what's going on and figure it out and make a plan" (P11, academic educator). Nurse educators also recognized the need to collect data to guide future decision making: "Okay, we're making changes, how are we actually collecting data or outcomes or some sort of piece to say that this is a viable option" ( $\mathrm{P} 4$, clinical educator).

\section{Struggling to Stay Afloat}

Nurse educators faced significant emotional and mental well-being challenges in the workplace and at home because of the pandemic. Overwhelming work demands, longer working hours, and unsustainable workloads left educators feeling emotionally and physically drained:

The demands on me are much greater. The increased workload is much more noticeable.

The hours are much longer. The requirement to make quick decisions in a rapidly evolving environment are much more evident... there's been a lot of trauma in relation to rapidly changing decisions that staff then have to manage... it's not actually sustainable. (P10, academic educator)

Notwithstanding this hard work, some nurse educators expressed feelings of guilt for not working a clinical position: "Just this guilt... because I'm not there on the front line... I know that the work I'm doing is important. But I just felt like I needed to be doing more and be out there" (P6, academic educator). Others expressed guilt about not meeting staff or student expectations: "Not being able to provide a consistent answer to staff questions. Not being able to be confident 
in the response that I would have at any given time" (P2, clinical educator). Participants also spoke of how these challenges extended into their personal or home life: "I think the biggest impact is probably on my family... Their fear of me working in that environment... I've had some friends that really do not want to come over as much anymore or connect or get too close" (P12, clinical educator). Some participants downplayed their emotions in front of others: "Trying to keep... that game face on for the staff. Trying to come home to your family and say, 'Yeah, it was okay. It was busy,' but you kind of downplay things a little bit" (P3, clinical educator). Others told stories of trying to overcome the inadequate support by overworking, but this work took a significant toll:

There's only so much time in a day, but there's these tasks that have to get done... I just worked and worked and worked. That's how I managed... I felt like a truck hit me. The toll that that takes on your physical body, it's exhausting. It hurts. It's like bone pain, deep. That fatigue. That is important to know. It's an unsafe and unsustainable way of working. (P11, academic educator)

The pandemic also surfaced an important but under-examined challenge of a largely female workforce and "illuminated the labour that women do with caring for their families and working... how all these economic re-opening pieces are still ignoring the fact that childcare is just such an essential piece of women returning to the workplace" (P6, academic educator). Many nurse educators were balancing their ongoing work demands with the new home demands created by the pandemic. With children no longer in childcare or school, nurse educators struggled to balance the increasing work and home demands.

Nurse educators spoke of ways in which they have been addressing their mental and emotional well-being. Self-care was commonly practised and included exercise, hobbies, and connecting with family or friends. The importance of connection with peers and reaching out to find a source of support was discussed. Protecting time away from work allowed participants to achieve a better work-life balance, including taking breaks from engaging with news or social media. Many participants highlighted the importance of being empathetic and compassionate with their team members and being kind with others while acknowledging the change in other peoples' lives: "Trying to acknowledge the humanity of people's lives have changed, and we have this expectation of all this work on top of it. And so not to be too demanding or too harsh around timelines" (P14, academic educator). These attitudes contrasted with the guilt experienced by other participants. The mental health and well-being challenges highlighted by nurse educators indicate this is an important area of ongoing concern that requires further supports.

\section{Lacking Support and Resources}

Nurse educators identified inadequate funding, time, and resources as barriers to their work. One participant described the pandemic as being "the perfect storm... it does come down to funding and acknowledging the complexity and cost of nursing, and funding it appropriately so that we can have enough staff to manage the demands" (P10, academic educator). There were also stories of inadequate personal protective equipment and staff being "told by their CEOs and managers to shut up and put up... that's not going to make anybody feel safe" (P15, academic educator). Nurse educators were responsible for trying to keep their staff safe, despite limited resources.

\section{Theme Four: Silver Linings}

\section{Shedding Light on the Value of Nurses}


Participants discussed the support from their community, colleagues, and the general public as a source of encouragement and motivation:

The support of the people in the rest of the hospital, it was just incredible. The amount of people that came back from other areas and other jobs, and just basically came in and said, "Tell me what to do. Tell me where to go." I thought it was incredible. (P3, clinical educator)

In contrast to participants who felt they did not have support and resources, some participants were grateful for nurse leaders who listened to and invested in their teams during this time of uncertainty: "They have been... just amazing in that sense that they've looked after individuals, they've listened to concerns. And that I think in a leadership role is huge, is listening to the people" (P6, academic educator). The value of nurses and nursing work in general was more profoundly illuminated for the nurses working in clinical areas when compared to the nurse educators working in academic settings who understood the clapping was for front-line healthcare workers.

Appropriate funding across different sectors was highlighted for ensuring a robust and well-educated nursing workforce. This process includes funding for nursing education, research, and workforce considerations:

Because you cannot on one hand say we're heroes and clap and bang pots or whatever, then on the same hand say, "Well, we're going to still cut positions. We're going to cut funding to education of nurses. We're going to devalue the profession. (P6, academic educator)

Participants believed it was important to have nurses involved in healthcare decisionmaking. COVID-19 demonstrated how critical nursing input can be to creating an effective response: "I always get a little bit concerned when it comes to government and senior leadership levels... do we have enough nursing focus within those roles" (P4, clinical educator). Policies and decisions that are made at a high level needed to take into consideration the nurses working clinically: "If there's just one person in this command post who could think through the process and maybe put it into a way that it's more easily communicated, that would've really changed what we were doing" (P1). Future planning and preparation could make use of nursing insights and perspectives; taking this pandemic as an opportunity to learn: "Well, that at any time, a pandemic can occur. And now that we've had this experience, it's important to be prepared and somehow have a plan or a strategy in our back pocket to how would we adapt again in the future" (P14, academic educator). Participants hoped that nurses would be involved in future planning to improve the pandemic response.

\section{Increasing Collaboration}

Participants reported increased collaboration as one of the positive aspects of the pandemic. Interdisciplinary strategies were reported as beneficial: "One of the best things... that has come with this is actually meeting so many new people... and working together for a common cause" (P12, clinical educator). Nurse educators spoke of the importance of keeping teamwork and collaboration moving forward, including "team-based policy, procedures, and research as opposed to being... siloed" (P4, clinical educator). Collaboration and teamwork need to extend beyond the interprofessional team to the working relationships between different health care agencies: "I think that other health services... needs to be more proactive and have a more proactive relationship 
with the unions because it really does impact the nurses and how we are functioning on the floors when there are conflicts between the two" (P1, clinical educator).

\section{Swimming Not Sinking}

With the onset of COVID, nurse educators faced immense challenges. Some participants enjoyed the challenge of working under pressure while others mentioned increased productivity as an outcome of their changed routine:

My own personal work, it may have actually improved... Because I do not have all the meetings and such that I might've had on campus... I've been able to, in a way, focus on some of the writing that I wanted to. (P6, academic educator)

The changes that nurses had to make were not wholly negative and some participants found their new working patterns were beneficial.

\section{Discussion}

Nurse educators in this study acknowledged their unique experiences in the COVID-19 pandemic. They highlighted the changes, challenges, outcomes, and recommendations for moving forward. An important issue for these participants was the visibility of nurse educators. They are instrumental to pandemic response, yet nurse educators have had a much lower profile when compared to other health professionals (Daly et al., 2020). Carryer (2020) argued that nurses are frequently not procuring a place at the table, even when issues directly affect nurses and nursing work. While the COVID-19 pandemic forced nurse educators to rapidly adapt their work, their experiences and challenges remain largely unrecognized.

Nurse educators adapted rapidly to changing work roles, delivery methods, and educational content. The changes to clinical practice and education are occurring at rapid speed and scale, especially when contrasted with the glacial speed of the pre-COVID era (Thornton, 2020). While the situation is challenging, this disruption has created the opportunity to use innovative pedagogical approaches and advance nursing and nursing education in new and creative ways that embrace technology and flexible learning (Hassmiller et al., 2020; Institute of Medicine, 2011).

Participants in this study cited collaboration as a major source of support for their work. Professional camaraderie has been noted amongst colleagues working together during a pandemic (Fernandez et al., 2020). Within the context of turmoil, there is often an increased level of cooperation and collaboration among health care workers across professions (Langlois et al., 2020). Students from across health care professions have also described an increased level of collaboration in responding to COVID-19 (Langlois et al., 2020). The current pandemic offers a unique opportunity for nurse educators to foster interprofessional collaboration and education. The shift toward virtual care models invites educators to consider the impact on interprofessional team relationships and new virtual platforms to facilitate education (Langlois et al., 2020).

The nurse educators in our study reported challenges in managing the constantly changing COVID-19 guidelines. Rapidly changing advice and knowledge can increase stress levels, exacerbate anxiety, and result in burnout (Fernandez et al., 2020; Hu et al., 2020). The reasons for such adverse psychological outcomes may also be due to excessive workload, inadequate personal protective equipment, and over-engagement with social media and news, as well as people feeling inadequately supported (Spoorthy et al., 2020). Maintaining the mental health of nurse educators is essential to maintain nursing education in both academic and clinical settings. 
Nurse educators working in academia expressed a heightened and acute sense of guilt for not contributing as front-line health care workers during the pandemic. This finding was parallel to ideas shared by Dewart and colleagues (2020), highlighting that registered nurses were grappling with guilt from wanting to provide front-line care while understanding their role in educating nurses would add much needed numbers of registered nurses to the strained nursing workforce. It is important to acknowledge nurse educators as key to maintaining the nursing workforce and understand they also faced significant challenges as a result of the pandemic. Exploring and understanding nurse educators' guilt during the pandemic is an important area for future research.

Maintaining the mental health of nurse educators is essential to persevering through COVID-19. Pandemics can exert significant psychological impacts on front-line workers, including nurse educators. Leaders need to pay attention to work stress and the related factors that are negatively impacting nurse educators' mental health and well-being. Protecting the well-being of nurse educators through appropriate measures is a crucial tool to maintaining essential nursing education in both academic and clinical settings.

\section{Limitations}

The results of this study need to be interpreted within the context of the study's limitations. We were limited to sampling nurse educators who had responded to our initial PANDEMIC study survey. Participants were self-selected, potentially limiting the representation of nurse educator perspectives. Although nurses from diverse backgrounds completed our survey, the sample of nursing educators who agreed to participate in this qualitative study were female, most were White, and they were highly educated. We do not know if nurses from diverse backgrounds, including male nurses, have similar experiences. Comparison with educators from other health care disciplines would strengthen the research, as would exploring the perspectives from a larger sample of nurse educators over time.

\section{Implications}

The results from this study will be useful to several target audiences, including nurse educators in clinical and academic settings, institutional decision makers, and researchers. For example, nurse educators may use our findings to engage in conversations, establish plans for harnessing the teaching and learning innovations developed through the pandemic for future teaching opportunities, and foster critical reflection about the impact of the pandemic on nursing education practice. Institutional decision makers may use these findings to guide supports for nurse educators targeted specifically to meet their needs, amplify conversations about the importance of nurse educator work, and develop strategies to foster the success and impact of nurse educator work during these unprecedented circumstances. For researchers, the findings may be used to inform future research on nurse educators' experiences during disasters, including the experiences of guilt, diversity, and gender.

\section{Conclusion}

COVID-19 has resulted in increasingly complex changes to nurse educators' work in both academic and clinical environments. While the participants in this study recognized the importance of their work, more consideration of the challenges experienced by nurse educators is required to help support them through these rapidly changing times. Addressing the lack of time, resources, 
Quality Advancement in Nursing Education - Avancées en formation infirmière, Vol. 7, Iss. 2 [2021], Art. 8

and supplies as well as the challenges to maintaining overall mental health and wellbeing is essential to protecting nursing education and the nursing profession. 


\section{References}

Braun, V., \& Clarke, V. (2006). Using thematic analysis in psychology. Qualitative Research in Psychology, 3, 77-101.

Carnevale, F. A. (2016). Authentic qualitative research and the quest for methodological rigour. Canadian Journal of Nursing Research, 34(2), 121-128.

Carryer, J. (2020). Letting go of our past to claim our future. Journal of Clinical Nursing, 29, 287-289. https://doi.org/10.1111/jocn.15016

Costa, R., Lino, M. M., Souza, A., Lorenzini, E., Fernandes, G. C. M., Brehmer, L. C., Vargas, M., Locks, M. O. H., \& Gonçalves, N. (2020). Nursing teaching in COVID-19 times: How to reinvent it in this context? Texto \& Contexto Enfermagem, 29. https://doi.org/10.1590/1980-265x-tce-2020-0002-0002

Creswell, J. (2014). Research design: Qualitative, quantitative, and mixed methods approaches (4th ed.). Sage.

Daly, J., Jackson, D., Anders, R., \& Davidson, P. M. (2020). Who speaks for nursing? COVID19 highlighting gaps in leadership. Journal of Clinical Nursing, 29(15-16), 2751-2752. https://doi.org/10.1111/jocn.15305

Dewart, G., Corcoran, L., Thirsk, L., \& Petrovic, K. (2020). Nursing education in a pandemic: Academic challenges in response to COVID-19. Nurse Education Today, 92, 104471. https://doi.org/10.1016/j.nedt.2020.104471

Fernandez, R., Lord, H., Halcomb, E., Moxham, L., Middleton, R., Alananzeh, I., \& Ellwood, L. (2020). Implications for COVID-19: A systematic review of nurses' experiences of working in acute care hospital settings during a respiratory pandemic. International Journal of Nursing Studies, 103637. https://doi.org/10.1016/j.ijnurstu.2020.103637

Hachey, A., Wladis, C., \& Conway, K. (2012). Is the second time the charm? Investigating trends in online re-enrolment, retention and success. The Journal of Educators Online, 9(1). https://doi.org/10.9743/jeo.2012.1.2

Hassmiller, S. B., Beauvais, A. M., \& Shellenbarger, T. (2020). The future of nursing report 10 years later: Where is nursing and what work remains? Nursing Education Perspectives, 41(5), 272-273. https://doi.org/10.1097/01.NEP.0000000000000724

Hu, D., Kong, Y., Li, W., Han, Q., Zhang, X., Zhu, L. X., Wan, S. W., Liu, Z., Shen, Q., Yang, J., He, H. G., \& Zhu, J. (2020). Frontline nurses' burnout, anxiety, depression, and fear statuses and their associated factors during the COVID-19 outbreak in Wuhan, China: A large-scale cross-sectional study. EClinicalMedicine, 24, 100424. https://doi.org/10.1016/j.eclinm.2020.100424

Institute of Medicine. (2011). The future of nursing: Leading change, advancing health. National Academies Press.

Jacobsen, M., Brown, B., \& Lambert, D. (2013). Technology-enhanced learning environments in higher education: A review of the literature. Werklund School of Education, University of Calgary. http://hdl.handle.net/1880/52244 
Johnson, B. R., \& Onwuegbuzie, A. J. (2004). Mixed methods research: A research paradigm whose time has come. Educational Researcher, 33(7), 14-26. http://dx.doi.org/10.2307/3700093

Klar, R. T. (2020). Nursing educators as agents of change in the SARS-CoV2 pandemic. Nursing for Women's Health, 24(4), 253-255. https://doi.org/10.1016/j.nwh.2020.05.010

Langlois, S., Xyrichis, A., Daulton, B. J., Gilbert, J., Lackie, K., Lising, D., MacMillan, K., Najjar, G., Pfeifle, A. L., \& Khalili, H. (2020). The COVID-19 crisis silver lining: Interprofessional education to guide future innovation. Journal of Interprofessional Care, 1-6. https://doi.org/10.1080/13561820.2020.1800606

Miles, M. B., Huberman, A. M., \& Saldana, J. (2014). Qualitative data analysis: A methods sourcebook (3rd ed.). Sage.

Morse, J. M. (2015). Critical analysis of strategies for determining rigor in qualitative inquiry. Qualitative Health Research, 25(9), 1212-1222. https://doi.org/10.1177/1049732315588501

Nashwan, A. J., Mohamed, A. S., \& Kelly, D. R. (2020). Editorial: Nursing education in the Emergence of COVID-19. Open Journal of Nursing, 10, 595-597.

National League for Nursing. (2017). Faculty census survey 2017. http://www.nln.org/docs/default-source/default-document-library/disposition-of-full-timenurse-educators-by-gender-2017.pdf? sfvrsn $1 / 40^{1 / 2}$

Nowell, L. (2015). Pragmatism and integrated knowledge translation: Exploring the compatibilities and tensions. Nursing Open, 2(3), 141-148. https://doi.org/10.1002/nop2.30

Oblinger, D. G., \& Hawkins, B. L. (2006). The myth about online course development: A faculty member can individually develop and deliver an effective online course. Educause Review, 41(1), 14-15. Retrieved from https://net.educause.edu/ir/library/pdf/ERM0617.pdf

Spoorthy, M. S., Pratapa, S. K., \& Mahant, S. (2020). Mental health problems faced by healthcare workers due to the COVID-19 pandemic-A review. Asian Journal of Psychiatry, 51, 102119. https://doi.org/10.1016/j.ajp.2020.102119

Sword, T. S. (2012). The transition to online teaching as experienced by nurse educators. Nursing Education Perspectives, 33(4), 269-271.

Thornton, J. (2020). Covid-19: How coronavirus will change the face of general practice forever. British Medical Journal, 368, m1279. https://doi.org/10.1136/bmj.m1279

Topolovec-Vranic, J., \& Natarajan, K. (2016). The use of social media in recruitment for medical research studies: a scoping review. Journal of Medical Internet Research, 18(11), e286. https://doi.org/10.2196/jmir.5698 